\title{
SEMIÓTICA E IDEOLOGIA
}

\author{
Semiotics and ideology
}

Jean Cristtus PORTELA ${ }^{1}$

Resumo: A relação da semiótica com a noção de "ideologia", tal como é concebida nas teorias do discurso de origem marxista, inexiste e pareceria inapropriadamente redundante, a depender do ponto de vista adotado. A recusa à ideologia é patente nos objetos de análise e nos problemas de pesquisa da primeira semiótica de A. J. Greimas. Essa primeira semiótica se interessou por objetos de análise literários desconectados, com raras exceções, de sua época e de uma dimensão sóciopolítica explicitada. Quando, sobretudo a partir dos anos 1980, a semiótica passou a se interessar mais sistematicamente por objetos da comunicação social, o termo "ideologia" já caíra em desuso, vítima de sua polissemia, em certas práticas de análise discursiva, sem nunca ter sido realmente operatório nos estudos semióticos, salvo por sua acepção como busca de um objetovalor por parte dos sujeitos narrativos. Neste artigo, esboçamos uma breve história da relação da semiótica com a ideologia, refletindo sobre o modo como a semiótica brasileira precocemente (E. Lopes, J. L. Fiorin e D. P. de Barros) se ocupou dessa questão, antecipando preocupações que a semiótica europeia veio reencontrar em sua prática contemporânea mais recentemente.

Palavras-chave: Semiótica discursiva. Ideologia. História da semiótica. Discursos sociais.

\begin{abstract}
In semiotics, the notion of "ideology" as it is conceived in Marxist discourse theories does not exist and would seem inappropriately redundant depending on the adopted point of view. It is evident that the concept of ideology was refused in objects of analysis and research problems by the first wave of semiotic studies performed by A. J. Greimas. With rare exceptions, this first wave was concerned with literary objects of analysis that were disconnected of their time and their explicit socio-political dimensions. In the 1980s, when semiotics had become more systematically interested in objects of analysis related to the mass media, the term "ideology" fell into disuse, victim of its polysemy caused by certain discursive practices of analyses; therefore, it has never been an operative concept in semiotic studies, except for its understanding as a pursuit of an object of value by the narrative subjects. In the present paper, we will outline a brief history of the semiotics and the concept of "ideology", reflecting about how early Brazilian semiotics (E. Lopes, J. L. Fiorin and D. P. de Barros) dealt with this issue, anticipating concerns which European semiotics rediscovered more recently in its contemporary practice.
\end{abstract}

Keywords: Semiotics of discourse. Ideology. History of semiotics. Social discourses. 
Para que serve conservar com tanto cuidado o meio se nos desligamos do fim?

É. Durkheim (2016, p. X)

Neste artigo, discutirei algumas ideias que têm me interpelado, quando não perseguido, desde que analiso discursos literários e sociais na perspectiva da semiótica. Essas ideias dizem respeito ao modo como a semiótica discursiva aborda a ideologia e à própria ideologia que a semiótica veicula, explicitamente ou implicitamente, sobre o que é analisar discursos e, sobretudo, por que razão e para quê analisamos discursos, sejam eles literários, políticos ou religiosos.

Essa reflexão deixou de ser meu grilo falante e foi promovida a objeto mais formal de reflexão por um episódio que me aconteceu há alguns anos. Após uma reunião de trabalho com uma orientanda ${ }^{2}$, em que discutimos longamente o modo como as "desnotícias" humorísticas que ela analisava pressupunham diferentes competências de leitura segundo os discursos que mobilizam, ela me dirigiu, enquanto nos despedíamos à porta, uma questão simples, mas intrigante, enquanto a porta se fechava, rangendo lentamente, como se antecipasse o que viria a seguir: "Professor, vou continuar a análise, mas... E a ideologia?".

"E a ideologia?". Via-se que era uma pergunta sincera, o que não me impediu de me sentir um pouco perplexo e me provocou um certo riso nervoso.

"E a ideologia?". Parte de mim pretendeu deserdá-la, dando-lhe uma resposta nonsense, como num koan zen, ou, ainda, respondendo-lhe como o Cristo a Felipe, em João 14:9: "Há tanto tempo que estou convosco, e ainda não me conheces?". Outra parte recebeu a pergunta sobre a ideologia com reverência, gravidade e gratidão, que devem ficar evidentes nestas reflexões.

Já chamada de burguesa e alienada nos anos 1960, por causa do seu programa então estruturalista, seria o caso agora de chamá-la de "coxinha" ou "isentona"? Estaria a semiótica no "centrão" das teorias do discurso? Ou na bancada parlamentar do "boi" gordo do quadrado semiótico e da "bala" do programa narrativo? A Escola de Paris é uma escola sem partido? E por fim, mais objetivamente: o que uma "semiótica da ideologia" teria a dizer sobre a "ideologia da semiótica"?

2 Refiro-me a Karina Rocha Campos, hoje doutoranda no Programa de Pós-graduação em Linguística e Língua Portuguesa da UNESP de Araraquara, que à época desenvolvia sua dissertação de Mestrado (CAMPOS, 2019). 


\section{Semiótica da ideologia?}

Na semiótica do discurso, pode-se dizer que a denominação "semiótica da ideologia" inexiste e soaria seja como inapropriadamente redundante seja como contraditória, a depender da sensibilidade do ouvinte. Inapropriada e redundante, pois o objeto da semiótica, o discurso, já pressupõe a ideologia. Contraditória, pois, historicamente, a semiótica dos anos 1960 e 1970 buscou se apartar do problema da ideologia, o que imprimiu uma marca duradoura na semiótica de nossos dias, especialmente como praticada na França, onde falar de ideologia para certos semioticistas ainda é sinal de infidelidade, quando não de senilidade.

Essa recusa à ideologia, para não dizer recalque, está muito presente nos objetos de análise e nos problemas de pesquisa da primeira semiótica de Greimas. Essa primeira semiótica se interessava por objetos de análise etnoliterários e literários e, frequentemente, desconectados de sua época. A preferência de Greimas por Guy de Maupassant, por exemplo, é conhecida (GREIMAS, 1976). Do mesmo modo como outros importantes pesquisadores do grupo greimasiano, como C. Zilberberg (1988a, 1988b), D. Bertrand (1985, 2000 ou J. Fontanille (1987), dedicaram bastante atenção, respectivamente, às obras de Rimbaud, Valéry, Zola e Proust, entre outros. Nos anos 1980, quando a semiótica, na França, passou a se interessar por objetos predominantemente sociais, a partir dos trabalhos de E. Landowski (1989) e J.-M. Floch (1990), seu "partido teórico" já estava tomado.

Esses objetos de análise literários e passadistas, ao lado da adoção de teses fortes do estruturalismo linguístico e antropológico, forjaram um programa de pesquisa que, nos primeiros anos da teoria, conseguiu, aparentemente, ignorar as reflexões sobre sujeito, ideologia, discurso, história e memória, que inflamaram a Paris de seus contemporâneos. Essas reflexões foram julgadas - e talvez para alguns ainda sejam - como externas ou transcendentes em relação à linguagem, que, para a semiótica, deve receber um tratamento imanente, voltado para a regularidade dos sistemas ou para a singularidade dos processos.

É desse sonho estruturalista que nasceu o imaginário teórico da primeira semiótica, cuja figuratividade teórica é geométrica e topológica e deu lugar a quadrados, losangos, esquemas, níveis, camadas, limites e limiares. O sentido era um objeto que era preciso cercar, isolar, decompor, hierarquizar, em suma, quantificar e topologizar. Não por acaso, a semiótica se desenvolveu a partir do nível semionarrativo, em que é mais evidente o trabalho de formalização e quantificação. 
Curiosamente, a semiótica narrativa da época se dotou de muitos conceitos para pensar a questão da ideologia: contrato, manipulação, competência, performance, sanção, fidúcia, veridiç̧ão, fazer persuasivo, fazer interpretativo, entre outros. Todos esses conceitos eram aplicados no interior das narrativas, nos limites do enunciado, sem grande interface com a enunciação, até porque, à época, a enunciação estava reservada ao nível discursivo e não aparecia como um problema pertinente no nível narrativo.

A semiótica formulou ferramentas que nos possibilitaram penetrar com bastante acuidade na constituição do universo de valores dos actantes das narrativas e conhecer de perto as suas motivações e finalidades. Não por acaso, a semiótica dessa época empregou timidamente o termo "ideologia", redefinindo-o no quadro do que chamamos "axiologia".

Para Greimas e Courtés (2008), a axiologia é um quadro geral de valores morais, lógicos, estéticos, entre tantos outros; é um conjunto de taxionomias (de classificações) a que se atribui valor. Por exemplo, a axiologia das formas físicas do corpo pressupõe um sistema de classificações que valoriza alguns estados e desvaloriza outros: "ter boa forma", "estar em forma", "não entrar em forma" ou "estar fora de forma", etc., são enunciados que exploram possibilidades de classificação dentro de um sistema de valores implícito que dispõe sobre o bom, sobre o justo, sobre o desejável, o viável, o inevitável. Portanto, esses enunciados pressupõem a existência de uma axiologia. A axiologia é, assim, definida como a teoria ou a descrição dos sistemas de valores, em seu modo de existência paradigmático, isto é, os valores são estabilizados ou arrolados em classes, em modelos, como possibilidades de uso.

É aí para a semiótica narrativa que entra a ideologia, que faz a axiologia tomar uma forma sintagmática e actancial. Sintagmática, pois implica escolhas e encadeamentos dos valores disponíveis em dada axiologia. Actancial, pois essas escolhas e encadeamentos só podem ser executados por um sujeito modalizado pelo querer ou pelo dever fazer.

Esse sujeito que faz ideologia, que age pela ideologia, não é uma mera posição, ele tem espessura de um sujeito (individual ou coletivo) que deseja ser e, consequentemente, deseja fazer de modo mais ou menos consciente. Para a semiótica, a ideologia é uma estrutura actancial que realiza a axiologia; é, em outros termos, a busca por um objeto de valor, a busca pela conjunção do sujeito com o seu objeto de predileção.

Se no exemplo precedente falamos que existe uma axiologia das formas físicas do corpo, agora podemos dizer que essa axiologia permite a existência de ideologias da "boa forma", de "quem se cuida", como se costuma dizer com certa perversidade na avaliação do que é o "cuidado", e também ideologias da "má forma", do "descuidado", do "largado", do "abandonado" ou do "relaxado" ou "de boa". 
A axiologia é paradigmática, pois fornece as classes valoradas gerais de avaliação e conduta; a ideologia é sintagmática, pois pressupõe um percurso actancial, de algum modo, eleito, desejado. Por essa razão, Greimas e Courtés (2008, p. 48) dirão que a "ideologia é uma busca permanente de valores", pois o sujeito ideológico deseja e, em desejando, deseja mais e diferentemente, o que explica o caráter, por vezes, contraditório e movente da ideologia.

Essa definição de ideologia, a despeito do seu grau de inventividade e operacionalidade, é completamente inusitada, se pensarmos que foi elaborada no final dos anos 1970, quando as concepções de L. Althusser já tinham, uma década atrás, reformado a natureza negativa, deformadora, da concepção marxista de ideologia e procuravam estabelecer uma teoria que, para além das ideologias particulares de classe, pudesse alcançar a análise da "ideologia em geral", realizada materialmente em aparelhos e práticas, como "relação imaginária de indivíduos com suas reais condições de existência" (ALTHUSSER, 1976, p. 122).

A definição de ideologia em semiótica não dialoga diretamente com a episteme discursiva de seu tempo. Greimas e Courtés são autores de uma generosidade tortuosa. E isso não por má-fé, mas, talvez, por excesso de fé (por ideologia!), por excesso de convicção no próprio projeto e por quererem se destacar de todas as teorias do discurso de potencial viés "social" ou "psicológico", para usar os seus próprios termos.

A semiótica, na época, como tantas outras teorias, adotou uma "retórica da teoria" (KOERNER, 1989, 2014; BATISTA, 2016) de silenciamento que é típica de programas científicos predatórios, que se pretendem revolucionários (MURRAY, 1994, 1988). Por exemplo: o Dicionário menciona duas vezes Foucault (verbetes "Episteme" e "Sociossemiótica", mas literalmente a mesma referência), uma vez M. Bakthin (verbete "Intertextualidade") e nenhuma vez M. Pêcheux.

Sem falar em ideologia, uma semiótica da ideologia manquée foi se firmando entre os greimasianos que já falavam de "mundo natural", de "universo socioletal", de "código cultural", e que passaram, a partir dos anos 1980, no contexto francês, a falar em "situação", "interação" e "opinião", graças à sociossemiótica de E. Landowski (1989).

\section{Ideologia à brasileira}

Nessa mesma época, três brasileiros pioneiros buscavam formas de pensar o ideológico e, portanto, o social no âmbito da teoria semiótica: Edward Lopes, em seu livro Discurso, texto e significação: uma teoria do interpretante, de 1978, José Luiz Fiorin, com 
sua tese de doutorado, A religião da imanência, de 1983, e Diana Luz Pessoa de Barros, com sua tese de livre-docência, A festa do discurso, de 1985. Para eles, resguardadas as particularidades das suas propostas, é ponto pacífico que o discurso é sempre ideológico.

Em grande medida dialogando com a AD francesa e com Bakhtin, Lopes (1978), Fiorin (1983) e Barros (1985) procuraram tratar a enunciação como a instância ideológica por excelência, o que revela a singularidade da semiótica brasileira em relação à francesa: enquanto os brasileiros tinham uma visão plural do fenômeno discursivo, a produção francesa se restringia cada vez mais, multiplicando patamares e categorias de análise no interior do seu próprio modelo.

Um exemplo da abertura da pesquisa brasileira em relação ao problema da ideologia é a tese de Fiorin que acabamos de mencionar, que propõe, de modo pioneiro na época, como nos lembra Beth Brait (2015, p. 5), a conjugação do semiótico e do ideológico, conferindo ao percurso gerativo do sentido greimasiano uma dimensão ideológica.

Afirma Fiorin (1983, p. 4), então com 36 anos, na "Introdução" da sua tese: "A hipótese deste trabalho é que o investimento ideológico se faz por meio dos mecanismos de enunciação, ao tematizarem-se e figurativizarem-se as estruturas semionarrativas. $O$ discurso seria o locus do investimento ideológico".

Posição ousada em começo de tese, em uma época em que os greimasianos europeus já tinham alojado a ideologia no âmbito "narrativo" como busca de objeto valor e começavam, sem nenhum entusiasmo pelo social, salvo por Landowski e Floch, a investir na chamada "semiótica das paixões", que culminaria na "virada fenomenológica da semiótica" e nos estudos sobre a tensividade.

A tese de Fiorin apresenta outra novidade para a época. De um modo, geral, desde Saussure e Hjelmslev, o dogma semiótico sempre foi a primazia da forma e a dificuldade de análise ou não pertinência da substância. Fiorin (1983, p. 171) em sua tese busca definir a ideologia como aquilo que nos escapa e que não se encerra puramente na forma linguística:

A dimensão ideológica é diferente das dimensões do sistema e do processo, porque busca, no uso do discurso, aquelas noções pelas quais se interessa uma teoria da substância. Se ela se confundisse com sintagmas e paradigmas, terse-ia reduzido a substância à forma. A dimensão ideológica é uma tentativa de colocar a substância no interior da teoria linguística. 
A esta altura, alguns pontos merecem recapitulação: a semiótica começou por ignorar o conceito de ideologia, chegou a redefini-lo no interior da semiótica narrativa, neutralizando sua dimensão social mais "extrovertida", seguiu na França, até hoje, sem querer saber dos aspectos ideológicos do discurso, mas possui uma derivação, esta no Brasil, que, desde cedo, procurou responder ao problema das relações entre discurso e sociedade, levando em consideração explícita ou implicitamente o problema da ideologia.

A semiótica da ideologia está esboçada, mesmo brevemente e com todas as suas contradições. Como ficaria, à guisa de conclusão, a ideologia da semiótica?

\section{A ideologia da semiótica}

A ideia de que a semiótica, com todo o poder heurístico da sua metalinguagem, não aborde o problema da ideologia está longe de ser exata. A semiótica não só dá conta do problema da ideologia, postulando-o à sua maneira, mas como o tornou obsoleto, na esteira do que aconteceu em algumas teorias do discurso, que, embora mencionem o conceito vez ou outra, acabaram por promovê-lo à peça de museu epistemológico, por ser muito geral, muito indistinto, muito polissêmico, muito enrijecido e totalizante ou pouco produtivo do ponto de vista metodológico.

Embora negligencie o uso do termo "ideologia" em sua fundação e em sua prática de análise, a semiótica se centra na problemática do valor na sua relação com o sujeito, seja como actante da narrativa seja como ator na enunciação. Nesse sentido, a semiótica se interessaria pela ideologia sem chamá-la pelo nome, uma pouco à moda da referência a Lord Valdemort, no Harry Potter, de J. K. Rowling: A ideologia é Aquela-Que-Não-DeveSer-Nomeada. Mas por que não deveria ou não poderia ser nomeada, a "ideologia"?

Porque essa nomeação implicaria assumir uma história conceitual bem mais do que centenária, que viu "ideologia" ser tudo, de "ideia científica" a "pré ou anti-científica", de "verdade de poucos" a "mentira", de "deformação" a "representação". E, talvez acima de tudo, porque a noção de ideologia pressupunha, no contexto científico-cultural em que a semiótica foi forjada, indivíduos de carne e osso que a ela respondem, que são interpelados por ela enquanto sujeitos, como dizemos desde Althusser (1976). A semiótica, aparentemente, tem uma conta a acertar com os "indivíduos", que ela vem compensando pelo estudo do corpo, das práticas e das formas de vida.

Em relação a seus propósitos, como teoria do discurso, a semiótica não poderia prescindir de uma reflexão sobre a ideologia que ela mesma engendra e representa, que, no 
início, se aproximou muito, figurativamente, de uma ideologia de cientista, uma ideologia de jaleco, de microscópio, de grau zero, de pureza e objetividade, em busca da construção de análises que não deveriam, dizem, sequer ser chamadas de "interpretações", mas de "proto-leituras". Nada mal para quem busca desvendar a "semiose", essa denominação, para alguns, a meio caminho da ciência de laboratório.

Para que serviria uma semiótica concebida sob o signo da objetividade e da isenção? Para fazer "enciclopédias", cogitou Umberto Eco (ECO; MAGLI, 1985). Seríamos os Novos Enciclopedistas? Nosso trabalho estaria terminado quando tivéssemos tudo catalogado, descrito e analisado? Felizmente não, pois no semioticista, no analista de discursos, se assoma a sua dimensão humana.

Para além da ideologia cientificista, Greimas (1979) nos sugeriu que o saber e, portanto, a semiótica só teria sentido enquanto "busca e generosidade". Esse mesmo Greimas, bastante coerente, aliás, no final da vida, maravilhado com milagres éticos e estéticos, pedia "mais luz" na consideração do mundo que nos cerca (GREIMAS, 2002).

Da ideologia do cientista, passamos àquela do humanista e talvez à do sensualista libertário (sensualista no sentido filosófico, que fique bem entendido) encantado com a tela do parecer.

Podemos dizer que a semiótica, como todo discurso ou teoria do discurso, tem uma dimensão ideológica, dimensão e fagulha que, na minha hipótese, restaria a reacender e a explicitar.

Não sem hesitação, a semiótica deverá assumir a sua vocação mundana e cidadã. A vocação ideológica da semiótica, como disciplina de crítica, emancipação e intervenção, é inequívoca. Essa vocação é, no fundo, de uma ideologia mudada em utopia. Uma teoria que trocou a noção de verossimilhança pela de eficácia não haverá de se iludir facilmente.

Que o semioticista também não se exceda em sua verve de moralista, a ideologia da semiótica só pode ser concebida como radicalmente emancipatória, pois nos revela as cadeias profundas da destinação e nos esclarece sobre o valor do valor.

Emancipação, nesse sentido, não é só autonomização, mas desconstrução. Desconstrução como contraprograma a todos os mecanismos de exclusão e de estabilização e naturalização dos valores e das identidades.

A análise, como divisão em partes, segundo a concepção hjelmsleviana, é o terreno dessa desconstrução. 
Análise, como diz Fiorin, "não é investigação policial" (FIORIN, 2007, p. 49), "nem a indignação nem a revolta contra (as) discriminações substitui a análise", como defende Landowski (2002).

O semioticista, sob a destinação da semiótica e a coerção da semiótica-objeto, deverá encontrar a boa distância de observação, sabendo que sempre se serve a um senhor, quando não a dois. Na cruzada ideológica do semioticista, a análise será, tenhamos consciência ou não, ribalta, trincheira ou cadafalso.

\section{Referências}

ALTHUSSER, L. Positions. Paris: Éditions Sociales, 1976.

BARROS, D. L. P. de B. Festa do discurso: teoria do discurso e análise de redação de vestibulandos. 1985. Tese (Livre-docência) - Faculdade de Filosofia, Letras e Ciências Humanas, Universidade de São Paulo, São Paulo, 1985.

BATISTA, R. de O. A Historiografia da Linguística e a retórica dos linguistas: a força das palavras e seu valor histórico. Filologia e Linguística Portuguesa, São Paulo, v. 18, n. 2, p. 301-317, ago./dez. 2016.

BERTRAND, D. Précis de sémiotiques littéraire. Paris: Éditions Nathan HER, 2000.

BERTRAND, D. L'espace et le sens Germinal d'Émile Zola. Paris: Hadès-Benjamins, 1985.

BRAIT, B. Entre o semiótico e o ideológico. Bakhtiniana, São Paulo, v. 10, n. 3, p. 5-26, set./dez. 2015. Disponível em: http://www.scielo.br/pdf/bak/v10n3/2176-4573bak-10-03-0005.pdf. Acesso em: 10 jul. 2019.

CAMPOS, K. R. Prática desnoticiosa e veridicção: um estudo sobre o site Sensacionalista e o blog The Piauí Herald. 2019. Dissertação (Mestrado) - Faculdade de Ciências e Letras, Universidade Estadual Paulista "Júlio de Mesquita Filho", Araraquara, 2019. Disponível em: https://repositorio.unesp.br/handle/11449/180996. Acesso em: 18 set. 2019.

DURKHEIM, É. O individualismo e os intelectuais. São Paulo: EDUSP, 2016. 
ECO, U.; MAGLI, P. Sémantique greimassienne et encyclopédie. In: PARRET, H.; RUPRECHT, H.-G. (org.). Exigences et perspectives de la sémiotique: recueil d'hommages pour Algirdas Julien Greimas. 2 vols. Amsterdam: John Benjamins, 1985. p. 161-177.

FIORIN, J. L. Linguagem e ideologia. São Paulo: Ática, 2007.

FIORIN, J. L. A religião da imanência: uma leitura de discursos presidenciais (1964-1978). v. 1 e v. 2. São Paulo, 1983. Tese (Doutorado em Semiótica e Linguística Geral) - Faculdade de Filosofia, Letras e Ciências Humanas, Universidade de São Paulo, São Paulo, 1983.

GREIMAS, A. J. Da imperfeição. Tradução Ana Cláudia de Oliveira. São Paulo: Hacker Editores, 2002.

GREIMAS, A. J. Préface. In: HÉNAULT, A. Les enjeux de la sémiotique. Introduction à la sémiotique générale. Paris: PUF, 1979.

GREIMAS, A. J. Maupassant. La sémiotique du texte: exercices pratiques. Paris: Éditions du Seuil, 1976.

GREIMAS, A. J.; COURTÉS, J. Dicionário de semiótica. Tradução Alceu Dias Lima et al. São Paulo: Contexto, 2008.

FLOCH, J.-M. Sémiotique, marketing et communication: sous les signes les stratégies. Paris: PUF, 1990.

FONTANILLE, J. Le savoir partagé. Paris: Hadès-Benjamins, 1987.

KOERNER, E. F. K. Quatro décadas de historiografia linguística: estudos selecionados. Vila Real: Universidade Trás-os-Montes e Alto Douro; 2014.

KOERNER, E. F. K. Practicing Linguistic Historiography. Amsterdam, Philadelphia: John Benjamins, 1989.

LANDOWSKI, E. Présences de l'autre: essais de socio-sémiotique II. Paris: PUF, 1997.

LANDOWSKI, E. La société réfléchie: essais de socio-sémiotique. Paris: Seuil, 1989. 
LOPES, E. Discurso, texto e significação: uma teoria de interpretante. São Paulo: Cultrix, 1978.

MURRAY, S. O. American sociolinguistics: theorist and theory groups. Amsterdam, Philadelphia: John Benjamins, 1998.

MURRAY, S. O. Theory Groups and the Study of Language in North America. A social history. Amsterdam, Philadelphia: John Benjamins, 1994.

ZILBERBERG. C. Raison et poétique du sens. Paris : PUF, 1988a.

ZILBERBERG, C. Architecture, musique et langage dans "Eupalinos » de P. Valéry.: Documents de travail, n. 176-7, p. 11, 1988b.

\section{Agradecimentos}

Este trabalho foi desenvolvido com apoio do CNPq, processo n. 312227/2017-5, e da FAPESP, processo. n. 2016/22466-0.

COMO CITAR ESTE ARTIGO: PORTELLA, Jean Cristtus. Semiótica e ideologia.

Revista do GEL, v. 16, n. 1, p. 132-142, 2019. Disponível em: https:/ / revistadogel. gel.org.br/

DOI: http://dx.doi.org/10.21165/gel.v16i1.2778

Submetido em: 30/08/2019 | Aceito em: 20/11/2019. 